\title{
Skepticism about thrombolytics in stroke is not unreasonable
}

\section{Ryan P. Radecki}

I thank Donnan and colleagues for their comprehensive Review of the state and future of thrombolytic treatment for acute ischemic stroke (How to make better use of thrombolytic therapy in acute ischemic stroke. Nat. Rev. Neurol. 7, 400-409; 2011). ${ }^{1}$ The authors highlight an attitude of antagonism towards tissue plasminogen activator (tPA) among some emergency physicians. I wish to provide some justification for the dissenting opinion on which emergency physician reticence is based.

Of the early trials of thrombolytics for the treatment of acute stroke, only the National Institute of Neurological Disorders and Stroke (NINDS) trial demonstrated positive outcomes, and only after outcome measures were adjusted from 24 -h outcomes to 90-day outcomes for the second part of the trial. ${ }^{2}$ MAST-I, ASK, MAST-E, ECASS, ECASS II, and ATLANTIS failed to demonstrate that the benefits of thrombolysis outweighs the harm. ${ }^{3-8}$ Further published literature in support of the NINDS findings primarily takes the form of pooling data on patients from these heterogenous negative or equivocal trials who met the strict NINDS protocol definition of eligibility. ${ }^{9}$ Cautionary literature regarding the effectiveness of thrombolytics outside the context of research protocols illustrates the ease with which harm can outweigh benefits. ${ }^{10}$ Potential conflicts of interest are also extraordinarily prominent in the literature supporting the use of thrombolytics. For example, in ECASS III, 13 of 14 authors report receiving financial support from the manufacturer of the study drug, including three authors who are directly employed by Boehringer Ingelheim. ${ }^{11}$

In light of ongoing placebo-controlled trials, such as IST-3, thrombolytic therapy in acute ischemic stroke is, by definition, still experimental. The American Academy of Emergency Medicine position statement concluded that insufficient evidence is available to state whether or not thrombolytic therapy should be the standard of care in acute ischemic stroke. ${ }^{12}$ The American College of Emergency Physicians policy guideline recommends thrombolytics be used only in institutions in which a protocol for administering such treatment and a supporting framework for follow-up care are in place. ${ }^{13}$ In contrast to the handful of positive studies regarding thrombolysis for acute stroke, thrombolysis for acute myocardial infarction was evaluated in over 60,000 patients in trials prior to its acceptance in

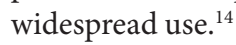

Revascularization of ischemic tissue and rescue of a still-viable penumbra are valid therapeutic goals, but the literature in support of thrombolytics in acute ischemic stroke should not be misrepresented. Rather than endeavor to treat more patients with systemic thrombolytic therapy, further research should focus on narrowing the treatment population to those who are most likely to benefit from this intervention.

The University of Texas Health Science Center-Houston, 6431 Fannin Street, JJL 450, Houston, TX 77030, USA. ryan.p.radecki@uth.tmc.edu

\section{Competing interests}

The author declares no competing interests.

1. Donnan, G. A. et al. How to make better use of thrombolytic therapy in acute ischemic stroke. Nat. Rev. Neurol. 7, 400-409 (2011).

2. [No authors listed]. Tissue plasminogen activator for acute ischemic stroke. The National Institute of Neurological Disorders and Stroke rt-PA Stroke Study Group. N. Engl. J. Med. 333, 1581-1587 (1995).

3. [No authors listed]. Randomized controlled trial of streptokinase, aspirin, and combination of both in treatment of acute ischemic stroke.
Multicenter Acute Stroke Trial—Italy (MAST-I) Group. Lancet 346, 1509-1514 (1995).

4. Donnan, G. A. et al. Streptokinase for acute ischemic stroke with relationship to time of administration: Australian Streptokinase (ASK) Trial Study Group. JAMA 276, 961-966 (1996).

5. [No authors listed]. Thrombolytic therapy with streptokinase in acute ischemic stroke. The Multicenter Acute Stroke Trial-Europe (MAST-E) Group. N. Engl. J. Med. 335, 145-150 (1996).

6. Hacke, W. et al. Intravenous thrombolysis with recombinant tissue plasminogen activator for acute hemispheric stroke. The European Cooperative Acute Stroke Study (ECASS). JAMA 274, 1017-1025 (1995).

7. Hacke, W. et al. Randomized double-blind placebo-controlled trial of thrombolytic therapy with intravenous alteplase in acute ischemic stroke (ECASS II). Second EuropeanAustralasian Acute Stroke Study Investigators. Lancet 352, 1245-1251 (1998).

8. Clark, W. M. et al. Recombinant tissue-type plasminogen activator (Alteplase) for ischemic stroke 3 to 5 hours after symptom onset. The ATLANTIS Study: a randomized controlled trial. Alteplase Thrombolysis for Acute Noninterventional Therapy in Ischemic Stroke. JAMA 282, 2019-2026 (1999).

9. Hacke, W. et al. Association of outcome with early stroke treatment: pooled analysis of ATLANTIS, ECASS, and NINDS rt-PA stroke trials. Lancet 363, 768-774 (2004).

10. Katzan, I. et al. Use of tissue-type plasminogen activator for acute ischemic stroke: the Cleveland area experience. JAMA 283. 1151-1158 (2000).

11. Hacke. W. et al. Thrombolysis with alteplase 3 to 4.5 hours after acute ischemic stroke. $N$. Engl. J. Med. 359, 1317-1329 (2008).

12. Goyal, D. G., Li, J., Mann, J. \& Schriger, D. L. Position Statement on the Use of Intravenous Thrombolytic Therapy in the Treatment of Stroke. American Academy of Emergency Medicine [online], http://www.aaem.org/ positionstatements/thrombolytictherapy.php (2002).

13. ACEP Board of Directors. Use of Intravenous tPA for the Management of Acute Stroke in the Emergency Department. American College of Emergency Physicians [online], http://www. acep.org/practres.aspx?id=29834 (2002).

14. Nee, P. A. Thrombolysis after acute myocardial infarction. J. Accid. Emerg. Med. 14, 2-9 (1997). 